\title{
AN INTEGRATED TYPE-2 FUZZY DECISION MODEL BASED ON WASPAS AND SECA FOR EVALUATION OF SUSTAINABLE MANUFACTURING STRATEGIES
}

\author{
Mehdi KESHAVARZ-GHORABAEE ${ }^{*}$, Kannan GOVINDAN²${ }^{2}$ Maghsoud AMIRI ${ }^{3}$, \\ Edmundas Kazimieras ZAVADSKAS ${ }^{4}$, Jurgita ANTUCHEVIČIENE 5 \\ ${ }^{1}$ Department of Management, Faculty of Humanities (Azadshahr Branch), \\ Gonbad Kavous University, Gonbad Kavous, Iran \\ ${ }^{2}$ Center for Sustainable Supply Chain Engineering, Department of Technology and Innovation, \\ University of Southern Denmark, Odense M, Denmark \\ ${ }^{3}$ Department of Industrial Management, Faculty of Management and Accounting, \\ Allameh Tabataba'i University, Tehran, Iran \\ ${ }^{4}$ Institute of Sustainable Construction, Vilnius Gediminas Technical University, \\ Sauletekio al. 11, LT-10223 Vilnius, Lithuania \\ ${ }^{5}$ Department of Construction Management and Real Estate, \\ Vilnius Gediminas Technical University, Sauletekio al. 11, LT-10223 Vilnius, Lithuania
}

Received 17 June 2019; accepted 26 August 2019

\begin{abstract}
One of the most essential topics for the present and future generations is sustainability. Today, because of threats made by traditional and old manufacturing practices, sustainability has become an essential topic in manufacturing companies. Attaining a sustainable manufacturing process requires making decisions about the strategies of manufacturing. In this paper, a novel integrated model is developed to evaluate sustainable manufacturing strategies. The proposed model is based upon two multi-criteria decision-making (MCDM) methods: WASPAS (Weighted Aggregated Sum Product ASsessment) and SECA (Simultaneous Evaluation of Criteria and Alternatives). Due to the uncertainty of evaluation process, we use interval type-2 fuzzy sets (IT2FSs). An example of evaluating sustainable manufacturing strategies is presented, and a sensitivity analysis is carried out for illustration of the developed approach and validation of it. The findings show the efficiency of the developed model, and based on the considered example, "Eco-efficiency" can be regarded as an effective strategy.
\end{abstract}

Keywords: environmental sustainability, sustainable manufacturing, manufacturing strategy, multi-criteria decision-making, interval type-2 fuzzy sets, WASPAS, SECA.

\section{Introduction}

Concerns about issues like resource consumption, environmental changes, and social problems have been increased in the past years. These concerns lead to emergence of new concepts called "Sustainable development" and "Sustainability". The sustainability concept is founded on three principal dimensions including economic development, social development and environmental protection (Mebratu, 1998).

Manufacturing sector is one of the most important sectors within the context of sustainability (Joung, Carrell, Sarkar, \& Feng, 2013). This is because of the volume of resources, materials and energy consumption, introducing new products that lead to generation of wastes and emissions during product life cycles, etc. of this sector (Ocampo \& Estanislao-Clark, 2014). Social, environmental and financial benefits of sustainable business practices are increasingly realized by many manufacturing companies. The definition of sustainable manufacturing, according to the United States Environmental Protection Agency [EPA] is stated as "the creation of manufactured products through economically-sound processes that minimize negative environmental impacts while conserving energy and natural resources. Sustainable manufacturing also enhances employee, community and product safety" (EPA, 2019). Based on the

*Corresponding author. E-mails: m.keshavarz_gh@yahoo.com;m.keshavarz@gonbad.ac.ir 
definition of the Canadian Manufacturing Sector Gateway [CMSG], "sustainable manufacturing promotes minimizing or eliminating production and processing wastes through eco-efficient practices, and encourages adopting new environmental technologies" (CMSG, 2019). Adopting sustainable manufacturing, regardless of these definitions, can help maintain the business, and benefits from it will be extensive. Not only will companies have a lower negative impact on the environment, society and economy, they can also be more productive.

The strategy of manufacturing enables companies to think and act over a long period, and can create a competitive advantage based on a set of performance measures (Porter, 1996). Considering sustainability as a modern and ideal way for manufacturing companies has led to new challenges for them in defining their strategies. Sustainable manufacturing helps the improvement of processes and products by taking into account economic growth, social well-being and environmental stewardship, simultaneously. Therefore, manufacturing companies can be confronted with problems of selecting and launching new manufacturing strategy based on the concept of sustainable manufacturing. There are different strategies for moving towards sustainability in manufacturing companies (Maxwell, Sheate, \& van der Vorst, 2006). However, the focus of the most studies is on the strategies concerning waste minimization and resource consumption (Abdul Rashid, Evans, \& Longhurst, 2008).

Since the evaluation of strategies is subject to series of procedures which usually involve several dimensions and criteria, it can be modeled as a multi-criteria decisionmaking (MCDM) problem. Determination of relative criteria weights and desirability of strategies according to a set of criteria is a major challenge when we want to select an appropriate strategy for sustainable manufacturing. This process will be more problematic if there are some incommensurable and conflicting criteria (Singh, Olugu, Musa, Mahat, \& Wong, 2016). In sustainable manufacturing, these criteria should reflect three pillars of sustainability i.e. economic, environmental and social. There are several MCDM techniques and methods to cope with this type of problem such as TOPSIS (Technique for Order of Preference by Similarity to Ideal Solution), VIKOR (in Serbian: VIšekriterijumska optimizacija i KOmpromisno Rešenje), WASPAS (Weighted Aggregated Sum Product ASsessment), PROMETHEE (Preference Ranking Organization METHod for Enrichment of Evaluations), COPRAS (COmplex PRoportional ASsessment), EDAS (Evaluation based on Distance from Average Solution), SECA (Simultaneous Evaluation of Criteria and Alternatives) and CRITIC (CRiteria Importance Through Intercriteria Correlation) (Keshavarz-Ghorabaee, Amiri, Zavadskas, Turskis, \& Antucheviciene, 2018; Mardani et al., 2015). Some of these methods are only used to appraise the performance of alternatives, some are used to calculate criteria weights, and some other can be utilized for both purposes.

The evaluation process in a company is usually fulfilled by an expert or a group of experts. Uncertainty is an inevitable aspect of assessments and judgements made by an expert. This uncertainty usually leads to imprecise and ambiguous information (Zhou, Dou, Zhang, Zhao, \& Tan, 2018). The theory of fuzzy sets was first expounded by Zadeh (1965) for modeling the uncertainty of information. The application of this theory has been very extensive in different fields especially in multi-criteria decision-making problems, and several MCDM techniques in uncertain environments have been modeled by fuzzy sets (Heydari, Honarbakhsh, Pajoohesh, \& Zangiabadi, 2018; P. Liu \& J. Liu, 2018). To increase the flexibility of modeling in an uncertain environment, some advanced forms of fuzzy sets have been proposed such as intuitionistic fuzzy sets (IFSs), hesitant fuzzy sets (HFS), q-rung orthopair fuzzy sets (q-ROFs) and type-2 fuzzy sets (T2FSs) (Liu, Chen, \& Wang, 2018; Liu \& Wang, 2018a, 2018b). According to different situations, we can use different forms of fuzzy sets. Interval type- 2 fuzzy sets (IT2FSs) are very applicable to decision-making problems as a reduced form of T2FSs (Celik, Gul, Aydin, Gumus, \& Guneri, 2015; Liu, Gao, \& Ma, 2019; Qin, 2019).

There have been several studies on the role of sustainability on the manufacturing processes and manufacturing strategies. Abdullah, Wan Mahmood, Md Fauadi, Ab Rahman, and Mohamed (2017) investigated the possibility of implementing sustainable manufacturing practices according to a comparison of current status of achievements and the level of priority of practices. They used a questionnaire survey to gather data from 51 palm oil mills (POMs) located in Malaysia. A factor analysis was performed for reduction of the number of sustainable manufacturing practices. They found well-being of employees has the highest impact regarding both current achievement and priority in POMs.

Bhanot, Rao, and Deshmukh (2017) developed a comprehensive framework to improve the enablers and decrease the barriers of sustainable manufacturing according to the opinions of professionals and academicians. They used the DEMATEL (DEcision MAking Trial and Evaluation Laboratory) and ISM (Interpretive Structural Modeling) methodologies to develop an integrated approach for designing a hierarchical structure of the considered system. A statistical analysis was utilized for validation of the barriers and enablers of planning and implementing sustainable manufacturing.

Singh, Olugu, Musa, and Mahat (2018) proposed a new methodology to evaluate sustainability in manufacturing companies based upon the fuzzy analytic hierarchy process (AHP) and FIS (Fuzzy Inference System) methods. They used BSC (Balanced ScoreCard) for categorization of the indicators identified from the literature. For gathering the opinions of decision-makers, some linguistic variables were used, and fuzzy AHP was utilized to find the importance of indicators. In the approach proposed by them, FIS was applied to obtain overall sustainability performance of manufacturing companies.

In addition to the above-mentioned, there have been some other studies on sustainable manufacturing that 
interested readers can refer to (Hamdan \& Cheaitou, 2017; Kumar, Shankar, \& Thakur, 2018; Ocampo, Clark, \& Promentilla, 2016; Rajak \& Vinodh, 2015; Shankar, Kumar, \& Kannan, 2016; Thirupathi \& Vinodh, 2016; Vimal \& Vinodh, 2016). One of the important studies in this field is the research of Abdul Rashid et al. (2008). They made a comparison of different strategies for sustainable manufacturing including material efficiency, eco-efficiency, resource efficiency, and waste minimization in detail. Because of the importance of the strategies considered in the research of Abdul Rashid et al. (2008), we also use them in the current study.

In this paper, we develop a novel methodology using the WASPAS and SECA methods to evaluate sustainable manufacturing strategy. For evaluation of sustainable manufacturing strategy, considering objective criteria weights as well as the subjective weights elicited from the judgments and assessments of decision-makers can be very helpful to get reasonable solutions. The aim of developing the methodology is to handle such evaluation problems in an uncertain environment. The SECA method is used to determine a set of objective weights for criteria and a set of scores which represent the performance of strategies. The decision-matrix is constructed using assessments of decision-makers based on some linguistic variables. In the literature, there have been different ways to define linguistic variables and handle their computational aspects (Liao, Xu, Herrera-Viedma, \& Herrera, 2018; Teng, Z. Liu, \& P. Liu, 2018; Wu, Xu, Ren, \& Liao, 2018; Xu, 2005; Xu \& Wang, 2017). Each of these ways has its advantages and disadvantages in modeling of uncertainty. In this study, interval type-2 fuzzy sets are used for computations related to the linguistic variables because of the flexibility of them in defining fuzzy membership values. The objective weights determined using SECA are combined with the subjective weights calculated based on decision-makers' assessments in the developed methodology. These combined weights lead to a more realistic decision-making process. Moreover, in the framework of the developed methodology, the WASPAS method gives a measure for evaluation of sustainable strategies in the form of IT2FSs. A new method is also presented in this study to obtain ranking values of IT2FSs. For final evaluation, we define an aggregated measure which is calculated by integrating performance scores of SECA and ranking values of the WASPAS measure. Using the proposed aggregated measure, we can provide more stable results in evaluation of sustainable manufacturing strategies.

The remainder of this study is organized as follows. In Section 1, the methodology is elaborately presented. In this section, firstly, some basics related to type-2 fuzzy sets, a new ranking method for IT2FSs and the steps of the SECA and WASPAS methods are presented, and then a novel approach is developed for evaluation of sustainable manufacturing strategy. In Section 2, a computational example is utilized for illustration of the steps and effectiveness of the developed approach. Section 3 examines the sensitivity of the results to changes of criteria weights. Finally, conclusions are discussed.

\section{Methodology}

This section firstly presents some basic principles of interval type-2 fuzzy sets and their mathematical operations. Secondly, a method for ranking IT2FSs is introduced. Then, the WASPAS and SECA methods are presented in two distinct sub-sections. Finally, a new approach is proposed to evaluate sustainable manufacturing strategies.

\subsection{Interval type-2 fuzzy sets}

Complexity of type-2 fuzzy sets introduced by Zadeh (1975) has led to increasing use of interval type-2 fuzzy sets as a special form of T2FSs. Application of interval type-2 fuzzy sets is very helpful in many problems drawn from actual events or situations, especially decisionmaking problems. Efficient modeling of the uncertainty of subjective assessments and judgements is achievable when interval type-2 fuzzy sets are utilized. In the modeling of uncertain systems and processes, the IT2FSs are more flexible than ordinary fuzzy sets.

A two-level membership function symbolized by $\mu_{F}(x)$ can be used to define an interval type-2 fuzzy set. This function consists of Upper Membership Function (UMF) and Lower Membership Function (LMF). FOU (Footprint of Uncertainty) of an interval type-2 fuzzy set is formed by UMF and LMF (Mendel, John, \& Liu, 2006). A trapezoidal IT2FS is defined with UMF and LMF which have trapezoidal shapes. Let $\widetilde{\widetilde{F}}$ be a trapezoidal interval type-2 fuzzy set. The representation of this IT2FS is depicted in Figure 1.

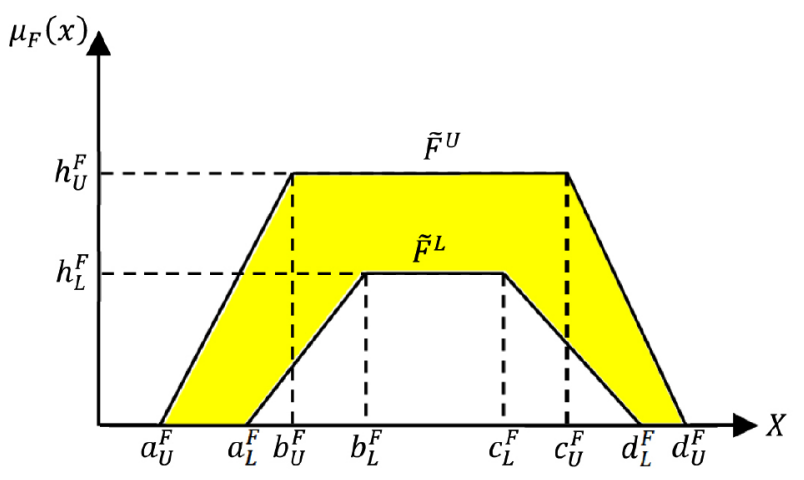

Figure 1. Trapezoidal IT2FS representation

This trapezoidal IT2FS can be defined using the following mathematical form:

$\widetilde{\widetilde{F}}=\left(\tilde{F}_{i} \mid i \in\{L, U\}\right)=\left(a_{i}^{F}, b_{i}^{F}, c_{i}^{F}, d_{i}^{F} ; h_{i}^{F} \mid i \in\{L, U\}\right)$.

According to Figure 1, $\tilde{F}_{L}$ and $\tilde{F}_{U}$ denote the LMF and UMF of $\widetilde{\widetilde{F}}$, respectively. Let $\widetilde{\widetilde{G}}$ be another trapezoidal IT2FS with similar definition, and $k$ be a crisp number, we can define some basic mathematical operations of 
IT2FSs as follows (Chen \& Lee, 2010; Keshavarz Ghorabaee, Amiri, Sadaghiani, \& Goodarzi, 2014; Keshavarz Ghorabaee, Amiri, Salehi Sadaghiani, \& Zavadskas, 2015): - Addition

$\widetilde{\widetilde{F}} \oplus \widetilde{\widetilde{G}}=\left(a_{i}^{F}+a_{i}^{G}, b_{i}^{F}+b_{i}^{G}, c_{i}^{F}+c_{i}^{G}, d_{i}^{F}+d_{i}^{G} ;\right.$

$\left.\min \left(h_{i}^{F}, h_{i}^{G}\right) \mid i \in\{L, U\}\right)$;

$\widetilde{\widetilde{F}}+k=\left(a_{i}^{F}+k, b_{i}^{F}+k, c_{i}^{F}+k, d_{i}^{F}+k ; h_{i}^{F} \mid i \in\{L, U\}\right)$.

- Subtraction

$\widetilde{\widetilde{F}} \odot \widetilde{\tilde{G}}=\left(a_{i}^{F}-d_{i}^{G}, b_{i}^{F}-c_{i}^{G}, c_{i}^{F}-b_{i}^{G}, d_{i}^{F}-a_{i}^{G} ;\right.$

$\left.\min \left(h_{i}^{F}, h_{i}^{G}\right) \mid i \in\{L, U\}\right)$;

$\widetilde{\widetilde{F}}-k=\left(a_{i}^{F}-k, b_{i}^{F}-k, c_{i}^{F}-k, d_{i}^{F}-k ; h_{i}^{F} \mid i \in\{L, U\}\right)$.

- Multiplication

$\widetilde{\widetilde{F}} \otimes \widetilde{\widetilde{G}}=\left(\min S_{1}, \min S_{2}, \max S_{2}, \max S_{1} ;\right.$

$\left.\min \left(h_{i}^{F}, h_{i}^{G}\right) \mid i \in\{L, U\}\right)$;

where $S_{1}=\left\{a_{i}^{F} a_{i}^{G}, a_{i}^{F} d_{i}^{G}, d_{i}^{F} a_{i}^{G}, d_{i}^{F} d_{i}^{G}\right\}$,

$S_{2}=\left\{b_{i}^{F} b_{i}^{G}, b_{i}^{F} c_{i}^{G}, c_{i}^{F} b_{i}^{G}, c_{i}^{F} c_{i}^{G}\right\}$,

$\widetilde{\widetilde{F}} \cdot k=\left\{\begin{array}{l}\left(a_{i}^{F} k, b_{i}^{F} k, c_{i}^{F} k, d_{i}^{F} k ; h_{i}^{F} \mid i \in\{L, U\}\right) \text { if } k \geq 0 \\ \left(d_{i}^{F} k, c_{i}^{F} k, b_{i}^{F} k, a_{i}^{F} k ; h_{i}^{F} \mid i \in\{L, U\}\right) \text { if } k<0\end{array}\right.$.

Using $k=1 / v \quad(v \neq 0)$, division operation of a trapezoidal IT2FS by a crisp number $v$ can also be defined according to Eq. (7).

- Exponentiation

$\widetilde{\widetilde{F}}^{\curlywedge k}=\left(\left(a_{i}^{F}\right)^{k},\left(b_{i}^{F}\right)^{k},\left(b_{i}^{F}\right)^{k},\left(c_{i}^{F}\right)^{k} ; h_{i}^{F} \mid i \in\{L, U\}\right)$.

- Defuzzification

$\tau(\widetilde{\widetilde{F}})=\frac{1}{2}\left(\sum_{i \in\{L, U\}} \frac{a_{i}^{F}+\left(1+h_{i}^{F}\right)\left(b_{i}^{F}+c_{i}^{F}\right)+d_{i}^{F}}{4+2 h_{i}^{F}}\right)$,

where $\tau(\widetilde{\tilde{F}})$ represents the score of $\widetilde{\widetilde{F}}$ in a crisp approximation.

\subsection{Ranking trapezoidal IT2FSs}

In this section, a method is proposed to rank trapezoidal interval type- 2 fuzzy sets. The foundation of the proposed ranking method is developed from a method proposed by Chu and Tsao (2002) in which a fuzzy set is ranked based upon the amount of space between the centroid point of a set and the original point. The current study uses the centroid of trapezoidal fuzzy sets presented by Wang, Yang, $\mathrm{Xu}$, and Chin (2006), and interval areas are calculated to compare trapezoidal IT2FSs and rank them. Suppose that we have $n$ trapezoidal IT2FSs $\left(\widetilde{\widetilde{E}}_{1}, \widetilde{\widetilde{E}}_{2}, \ldots, \widetilde{\widetilde{E}}_{n}\right)$, in the following, the proposed ranking method is delineated in a step-by step way:

Step 1: Calculate of the centroid of UMF and LMF of each set using the following equations.

$x c_{i t}=\frac{1}{3}\left[a_{i t}+b_{i t}+c_{i t}+d_{i t}-\frac{d_{i t} c_{i t}-a_{i t} b_{i t}}{\left(d_{i t}+c_{i t}\right)-\left(a_{i t}+b_{i t}\right)}\right]$,

$t \in\{L, U\}$

$y c_{i t}=\frac{h_{i t}}{3}\left[1+\frac{c_{i t}-b_{i t}}{\left(d_{i t}+c_{i t}\right)-\left(a_{i t}+b_{i t}\right)}\right], t \in\{L, U\}$,

where $\left(x c_{i U}, y c_{i U}\right)$ and $\left(x c_{i L}, y c_{i L}\right)$ are the centroid points of UMF and LMF of $i$ th fuzzy set $\left(\widetilde{\widetilde{E}}_{i}\right)$, respectively, and $i \in\{1,2, \ldots, n\}$.

Step 2: Compute interval areas according to the centroid points and the original point.

$$
\begin{aligned}
& A r_{i L}=\min \left(x c_{i L} y c_{i L}, x c_{i U} y c_{i U}\right) ; \\
& A r_{i U}=\max \left(x c_{i L} y c_{i L}, x c_{i U} y c_{i U}\right) .
\end{aligned}
$$

Step 3: Calculate of possibility degree of each pair of fuzzy sets over each other. Assume that $\widetilde{\widetilde{E}}_{s}$ and $\widetilde{\widetilde{E}}_{m}$ are two trapezoidal IT2FSs. The following equation is used in this step.

$$
p\left(\widetilde{\widetilde{E}}_{s} \geq \widetilde{\widetilde{E}}_{m}\right)=\left\{\begin{array}{lll}
1 & \text { if } & D_{N} \geq 0 \text { and } D_{P} \geq 0, \\
\frac{D_{P}}{D_{P}-D_{N}} & \text { if } & D_{N} \leq 0 \text { and } D_{P} \geq 0 \\
0 & \text { if } & D_{N} \leq 0 \text { and } D_{P} \leq 0
\end{array}\right.
$$

where $D_{N}=A r_{s L}-A r_{m U}, D_{P}=A r_{s U}-A r_{m L}$, and $p\left(\widetilde{\widetilde{E}}_{s} \geq \widetilde{\widetilde{E}}_{m}\right)$ is the possibility degree of $\widetilde{\widetilde{E}}_{s}$ over $\widetilde{\widetilde{E}}_{m}$.

Step 4: Obtain the ranking values of the fuzzy sets using the following formula $(\mathrm{Xu}, 2015)$.

$$
R v\left(\widetilde{\widetilde{E}}_{i}\right)=\frac{1}{n(n-1)}\left(\sum_{k=1}^{n} p\left(\widetilde{\widetilde{E}}_{i} \geq \widetilde{\widetilde{E}}_{k}\right)+\frac{n}{2}-1\right) .
$$

\subsection{The SECA method}

The SECA method is a recent method which seeks to evaluate the alternatives and criteria of a decision-making problem simultaneously. It gives a set of weights for the criteria and a set of performance scores for the alternatives. To apply the SECA method we just need a crisp decision matrix with $n$ alternatives and $m$ criteria shown as follows:

$$
X=\left[\begin{array}{cccccc}
x_{11} & x_{12} & \cdots & x_{1 j} & \cdots & x_{1 m} \\
x_{21} & x_{22} & \cdots & x_{2 j} & \cdots & x_{2 m} \\
\vdots & \vdots & \ddots & \vdots & \ddots & \vdots \\
x_{i 1} & x_{i 2} & \cdots & x_{i j} & \cdots & x_{i m} \\
\vdots & \vdots & \ddots & \vdots & \ddots & \vdots \\
x_{n 1} & x_{n 2} & \cdots & x_{n j} & \cdots & x_{n m}
\end{array}\right],
$$


where $x_{i j}\left(x_{i j}>0\right)$ denote the performance value of alternatives on criteria. The following are the steps of using SECA.

Step 1: Construct the normalized decision-matrix.

$$
X^{N}=\left[\begin{array}{cccccc}
x_{11}^{N} & x_{12}^{N} & \cdots & x_{1 j}^{N} & \cdots & x_{1 m}^{N} \\
x_{21}^{N} & x_{22}^{N} & \cdots & x_{2 j}^{N} & \cdots & x_{2 m}^{N} \\
\vdots & \vdots & \ddots & \vdots & \ddots & \vdots \\
x_{i 1}^{N} & x_{i 2}^{N} & \cdots & x_{i j}^{N} & \cdots & x_{i m}^{N} \\
\vdots & \vdots & \ddots & \vdots & \ddots & \vdots \\
x_{n 1}^{N} & x_{n 2}^{N} & \cdots & x_{n j}^{N} & \cdots & x_{n m}^{N}
\end{array}\right],
$$

where

$$
x_{i j}^{N}=\left\{\begin{array}{lll}
\frac{x_{i j}}{\max _{k} x_{k j}} & \text { if } & j \in B C, \\
\frac{\min _{k} x_{k j}}{x_{i j}} & \text { if } & j \in N C .
\end{array}\right.
$$

In Eq. (18), the sets of beneficial and non-beneficial criteria are denoted by $B C$ and $N C$, respectively.

Step 2: Calculate the degree of conflict between $j$ th criterion and the other criteria.

$$
\pi_{j}=\sum_{l=1}^{m}\left(1-r_{j l}\right),
$$

where $r_{j l}$ denotes the correlation between $j$ th and $l$ th columns of the normalized decision-matrix.

Step 3: Compute the standard deviation of each column of the normalized decision-matrix $\left(\sigma_{j}\right)$.

Step 4: Obtain the normalized values of $\sigma_{j}$ and $\pi_{j}$.

$$
\begin{aligned}
& \sigma_{j}^{N}=\frac{\sigma_{j}}{\sum_{l=1}^{m} \sigma_{l}} ; \\
& \pi_{j}^{N}=\frac{\pi_{j}}{\sum_{l=1}^{m} \pi_{l}} .
\end{aligned}
$$

Step 5: Solve the following multi-objective mathematical formulation to get the performance score of the alternatives $\left(S_{i}\right)$ and the objective weight of each criterion $\left(w_{j}\right)$.

$$
\begin{aligned}
& \max S_{i}=\sum_{j=1}^{m} w_{j} x_{i j}^{N}, \forall i \in\{1,2, \ldots, n\} ; \\
& \min \lambda_{b}=\sum_{j=1}^{m}\left(w_{j}-\sigma_{j}^{N}\right)^{2} ; \\
& \min \lambda_{c}=\sum_{j=1}^{m}\left(w_{j}-\pi_{j}^{N}\right)^{2} ; \\
& \text { s.t. } \sum_{j=1}^{m} w_{j}=1 ; \\
& w_{j} \leq 1, \forall j \in\{1,2, \ldots, m\} ; \\
& w_{j} \geq \varepsilon, \forall j \in\{1,2, \ldots, m\} .
\end{aligned}
$$

\subsection{The WASPAS method}

The WASPAS method integrates two multi-criteria decision-making model including WSM (Weighted Sum Model) and WPM (Weighted Product Model), and it has been used as an efficient MCDM method (Zavadskas, Turskis, Antucheviciene, \& Zakarevicius, 2012). Suppose that we have a decision-matrix like Eq. (16) with a number of alternatives $(n)$ and criteria $(m)$. Also $w_{j}$ denotes the importance of $j$ th criterion or weight of it. The following step-by-step procedure delineates this technique:

Step 1: Obtain linear normalization of performance values according to Eq. (18).

Step 2: Compute the values of $Q_{i}^{S}$ and $Q_{i}^{P}$ which represent the measures of WSM and WPM, respectively.

$$
\begin{aligned}
Q_{i}^{S} & =\sum_{j=1}^{m} w_{j} x_{i j}^{N} ; \\
Q_{i}^{P} & =\prod_{j=1}^{m}\left(x_{i j}^{N}\right)^{w_{j}} .
\end{aligned}
$$

Step 3: Calculate the WASPAS measure $\left(Q_{i}\right)$.

$$
Q_{i}=\gamma Q_{i}^{S}+(1-\gamma) Q_{i}^{P},
$$

where $\gamma$ is a parameter and $\gamma \in[0,1]$.

Step 4: Rank the alternatives according to decreasing values of $Q_{i}$.

\subsection{Proposed evaluation approach}

In this section, a novel integrated approach is proposed for multi-criteria decision-making under the assumption that the uncertainty of experts' judgments and opinions are captured through trapezoidal interval type-2 fuzzy sets. The proposed approach is founded upon the SECA and the WASPAS methods presented in the previous subsections. To use the proposed approach, an expert (decision-maker) or a group of experts should be assigned to define the decision-making problem. The expert(s) should make some subjective assessments for defining the problem. In the process of the proposed approach, SECA is used to find a set of objective weights for the criteria and a set of performance scores for the alternatives of the decision problem, and WASPAS is utilized for fuzzy evaluation of the alternatives. Objective criteria weights obtained by SECA are combined with the subjective weights that are calculated according to the estimations of the expert(s). The combined weights of criteria help the decisionmaker(s) to provide more realistic decisions. Moreover, based on the performance scores determined by SECA and the measure of the WASPAS method, an aggregated measure is calculated for each alternative. The alternatives then can be ranked according to the aggregated measure. Figure 2 shows the procedure of using the proposed approach.

According to Figure 2, the steps of using the proposed approach can be delineated as follows: 
Step 1: Establish a group of decision-makers (DMs). In this step, a group of experts are assigned to fulfill the decision-making process. These experts usually selected from the senior-level executives of an organization, or those positions that hold the most responsibility. Suppose that there is a group of $k$ decision-makers $\left(\mathcal{D}_{1}\right.$ to $\left.\mathcal{D}_{k}\right)$.

Step 2: Identify the alternatives and criteria for evaluation process. The group of decision-makers should collect data about the problem and extract the alternatives that need to be evaluated and the criteria which can cover different aspects of the alternatives. Assume that the problem involves $n$ alternatives $\left(\mathcal{A}_{1}\right.$ to $\left.\mathcal{A}_{n}\right)$ and $m$ criteria $\left(\mathcal{C}_{1}\right.$ to $\left.\mathcal{C}_{m}\right)$

Step 3: Assess the importance of each criterion. In this step, the importance or weight of every criterion should be assessed by every decision-maker. The decision-makers can express their opinions and judgements using linguistic variables. Let us denote by $\widetilde{w}_{j p}$ the importance of $j$ th criterion $\left(\mathcal{C}_{j}\right)$ given by $p$ th decision-maker $\left(\mathcal{D}_{p}\right)$.

Step 4: Assess the rating of all alternatives on all criteria. In this step, the decision-makers should also assess the alternatives on each criterion. Based on the type of the criteria, the assessments can be qualitative or quantitative. It should be noted that the focus of this study is on the qualitative and subjective assessments. Linguistic variables can also be utilized in assessing alternatives' performances. We will denote by $\widetilde{\widetilde{X}}_{i j p}$ the performance of $i$ th alternative $\left(\mathcal{A}_{i}\right)$ on $j$ th criterion $\left(\mathcal{C}_{j}\right)$ expressed by $p$ th decision-maker $\left(\mathcal{D}_{p}\right)$.

Step 5: Determine the subjective weights of criteria. Regarding the assessments made in Step 3, some linguistic

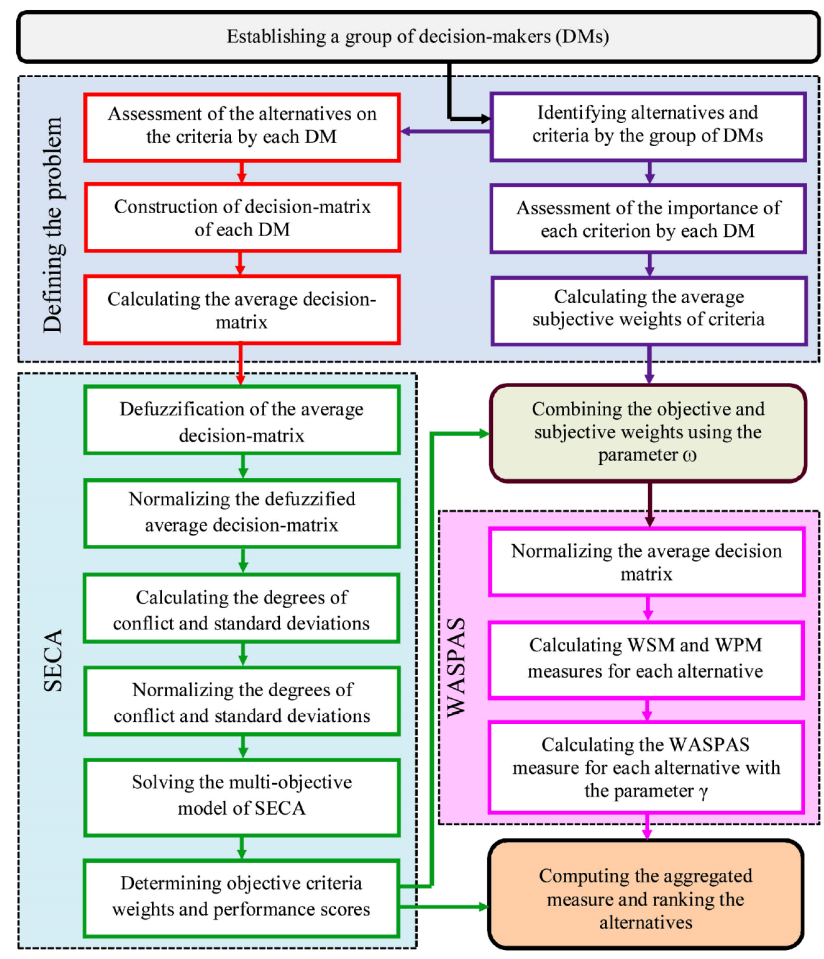

Figure 2. The framework of the proposed evaluation approach variables and the mathematical operations of trapezoidal IT2FSs presented in the previous section, the subjective weights of every criterion can be determined. The linguistic variables and the trapezoidal IT2FSs associated with them are defined in Table 1 . The following equation is applied to determine the average subjective weight of every criterion $\left(\tilde{\tilde{w}}_{j}^{s}\right)$.

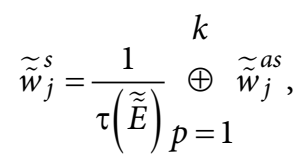

where

$$
\tilde{\tilde{w}}_{j}^{a s}=\frac{1}{k} \underset{p=1}{k} \widetilde{\tilde{w}}_{j p}^{s}
$$

and

$$
\widetilde{\widetilde{E}}=\underset{j=1}{m} \widetilde{\tilde{w}}_{j}^{a s} .
$$

Table 1. Linguistic variables and the corresponding trapezoidal IT2FSs

\begin{tabular}{|l|l|}
\hline Linguistic variable & \multicolumn{1}{|c|}{ Interval type-2 fuzzy sets } \\
\hline Very low $(\mathrm{VL})$ & $((0,0,0,0.1 ; 1),(0,0,0,0.05 ; 0.9))$ \\
\hline Low $(\mathrm{L})$ & $((0,0.1,0.15,0.3 ; 1),(0.05,0.1,0.15,0.2 ; 0.9))$ \\
\hline Medium low $(\mathrm{ML})$ & $((0.1,0.3,0.35,0.5 ; 1),(0.2,0.3,0.35,0.4 ; 0.9))$ \\
\hline Medium $(\mathrm{M})$ & $((0.3,0.5,0.55,0.7 ; 1),(0.4,0.5,0.55,0.6 ; 0.9))$ \\
\hline $\begin{array}{l}\text { Medium high } \\
(\mathrm{MH})\end{array}$ & $((0.5,0.7,0.75,0.9 ; 1),(0.6,0.7,0.75,0.8 ; 0.9))$ \\
\hline High $(\mathrm{H})$ & $((0.7,0.85,0.9,1 ; 1),(0.8,0.85,0.9,0.95 ; 0.9))$ \\
\hline Very high $(\mathrm{VH})$ & $((0.9,1,1,1 ; 1),(0.95,1,1,1 ; 0.9))$ \\
\hline
\end{tabular}

Step 6: Calculate the average decision-matrix. In this step, the decision-matrix associated with each decisionmaker is constructed, and according to the matrices, the linguistic variables that can be found in Table 1 and the mathematical operations related to trapezoidal IT2FSs, the average decision-matrix is calculated by utilizing the following formulas.

$$
\begin{aligned}
& \widetilde{\widetilde{X}}_{i j}=\frac{1}{k} \oplus \widetilde{\widetilde{X}}_{i j p}^{k} ; \\
& p=1 \\
& \bar{X}=\left[\widetilde{\widetilde{X}}_{i j}\right]_{n \times m} .
\end{aligned}
$$

Step 7: Defuzzify the average decision-matrix. To determine the objective criteria weights and performance scores of the SECA method, we have to obtain the defuzzified average decision-matrix $(\overline{X d})$ first. Based on the results of Step 6 and Eq. (9), this matrix can be calculated as follows:

$$
X d_{i j}=\tau\left(\widetilde{\tilde{X}}_{i j}\right) .
$$


Step 8: Normalize $\overline{X d}$, calculate the degrees of conflict and standard deviations for the criteria $\left(\sigma_{j}^{N}\right.$ and $\pi_{j}^{N}$ ) and solve the SECA model to obtain the objective criteria weights and performance scores of alternatives. Let us denote by $X d_{i j}^{N}, w_{j}^{0}$ and $S e_{i}$ the normalized values, objective weights and performance scores, respectively. The SECA model is solved here using the following mathematical model:

$$
\begin{aligned}
& \max Z=\lambda_{a}-\beta\left(\lambda_{b}+\lambda_{c}\right) ; \\
& \text { s.t. } \lambda_{a}=\sum_{i=1}^{n} S e_{i} ; \\
& S e_{i}=\sum_{j=1}^{m} w_{j}^{o} X d_{i j}^{N}, \forall i \in\{1,2, \ldots, n\} ; \\
& \lambda_{b}=\sum_{j=1}^{m}\left(w_{j}^{0}-\sigma_{j}^{N}\right)^{2} ; \\
& \lambda_{c}=\sum_{j=1}^{m}\left(w_{j}^{0}-\pi_{j}^{N}\right)^{2} ; \\
& \sum_{j=1}^{m} w_{j}^{0}=1 ; \\
& w_{j}^{0} \leq 1, \forall j \in\{1,2, \ldots, m\} ; \\
& w_{j}^{0} \geq \varepsilon, \forall j \in\{1,2, \ldots, m\},
\end{aligned}
$$

$\beta$ and $\varepsilon$ are two parameters of the model, and it is suggested to use $\beta=3$ and $\varepsilon=10^{-3}$ for solving the model.

Step 9: Combine the subjective objective criteria weights. Here, the subjective criteria weights described in Step 5 and the objective weights determined by the SECA method in Step 8 are fused together in this step to have more realistic weights for the criteria. The following formula with a combination parameter $\omega$ is used to compute the combined weights of criteria $\left(\widetilde{\tilde{w}}_{j}^{c}\right)$. It should be noted that Eqs (3) and (7) are utilized for the calculations.

$$
\tilde{\tilde{w}}_{j}^{c}=\omega \tilde{\tilde{w}}_{j}^{s}+(1-\omega) w_{j}^{0} \text {. }
$$

Step 10: Normalize the average decision matrix. In the classic WASPAS method, we use a linear normalization approach. However, because of using trapezoidal IT2FSs, the normalization approach is modified in this step, and the following equations are utilized to normalize the average decision-matrix.

$$
\widetilde{\widetilde{X}}_{i j}= \begin{cases}\frac{\widetilde{\tilde{X}}_{i j}}{\max _{i} X d_{i j}}, & \text { if } j \in B C, \\ 1-\frac{\widetilde{X}_{i j}}{\max _{i} X d_{i j}}, & \text { if } j \in N C .\end{cases}
$$

Step 11: Calculate WSM $\left(\widetilde{\tilde{Q}}_{i}^{S}\right)$ and WPM $\left(\widetilde{\tilde{Q}}_{i}^{P}\right)$ measures, and normalize them. This step is also a little different in the classic WASPAS method, and it is modified to handle trapezoidal IT2FSs' operations in an efficient way. The following equations are used in this step of the proposed approach.

$$
\begin{aligned}
& \widetilde{\tilde{Q}}_{i}^{S}=\underset{j=1}{m}\left(\widetilde{\widetilde{w}}_{j}^{c} \otimes \widetilde{\widetilde{X} n_{i j}}\right) ; \\
& \widetilde{\tilde{Q}}_{i}^{P}=\underbrace{m}_{j=1}\left(\left(1+\widetilde{\widetilde{X}}_{i j}\right)^{\curlywedge \tau\left(\tilde{\tilde{w}}_{j}^{c}\right)}\right) ; \\
& \widetilde{\tilde{Q}}_{i}^{S N}=\frac{\widetilde{\tilde{Q}}_{i}^{S}}{\max _{l} \tau\left(\widetilde{\tilde{Q}}_{l}^{S}\right)} ; \\
& \widetilde{\tilde{Q}}_{i}^{P N}=\frac{\widetilde{\widetilde{Q}}_{i}^{P}}{\max _{l} \tau\left(\widetilde{\widetilde{Q}}_{l}^{P}\right)} .
\end{aligned}
$$

Step 12: Compute the WASPAS measure. According to the normalized WSM and WPM measures and using the parameter $\gamma$, the WASPAS measure is calculated as follows:

$$
\widetilde{\tilde{Q}}_{i}=\gamma \widetilde{\widetilde{Q}}_{i}^{S N} \oplus(1-\gamma) \widetilde{\tilde{Q}}_{i}^{P N} .
$$

Step 13: Determine the aggregated measure $\left(A S_{i}\right)$ of the alternatives and rank them. In this step, the proposed ranking method is used to obtain ranking values of the WASPAS measure of the alternatives. Then these ranking values are merged with the performance scores obtained by the SECA method to get the aggregated measure of the alternatives.

$$
A S_{i}=R v\left(\widetilde{\widetilde{Q}}_{i}\right)+S e_{i} .
$$

\section{Evaluation of sustainable manufacturing strategies}

This section presents the application of the developed approach through a computational example. The example is related to the evaluation of sustainable manufacturing strategies in a company. Suppose that the company's plan is to select the best strategy to reach a sustainable manufacturing system. For this purpose, the company formed a group of experts consists of five specialists $\left(\mathcal{D}_{1}\right.$ to $\left.\mathcal{D}_{5}\right)$, which are called decision-makers hereafter, from different organizational departments. This group made a study on the subject and constructed the structure of the decision-making problem. Founded upon the study of Abdul Rashid et al. (2008) four sustainable manufacturing strategies $\left(\mathcal{A}_{1}\right.$ to $\left.\mathcal{A}_{4}\right)$ were designated for evaluation. These strategies include "Waste minimization", "Material efficiency", "Resource efficiency" and "Eco-efficiency". In addition, according to the studies of Vinodh and Jeya Girubha (2012a, 2012b), and Singh et al. (2016), nine criteria $\left(\mathcal{C}_{1}\right.$ to $\mathcal{C}_{9}$ ) were defined for evaluation of the strategies. The criteria and their descriptions are presented as follows: 
Implementation cost $\left(\mathcal{C}_{1}\right)$ : This criterion is associated with the costs incurred in implementing the selected strategy. Although the implementation cost is naturally a quantitative criterion, the decision-makers can express their subjective estimation.

Profits $\left(\mathcal{C}_{2}\right)$ : This criterion includes the level of profits that the decision-makers expect from establishing the selected strategy.

Adaptability $\left(\mathcal{C}_{3}\right)$ : This criterion is related to how adaptable the selected strategy is to the circumstances of the organization and different aspects of it.

Wastage $\left(\mathcal{C}_{4}\right)$ : This criterion is about the amount or proportion of waste or lost that the decision-makers expect from selection of a strategy.

Emissions $\left(\mathcal{C}_{5}\right)$ : This criterion is associated with the possible amount of greenhouse gasses emitted by selection of a strategy.

Energy usage $\left(\mathcal{C}_{6}\right)$ : This criterion is associated with the expected amount of energy utilized by selecting a strategy.

Workplace safety $\left(\mathcal{C}_{7}\right)$ : This criterion is related to how effective the selected strategy is in improving the safety of the workplace and employees.

Employees' acceptance $\left(\mathcal{C}_{8}\right)$ : This criterion is about the general agreement of employees. If the employees of an organization believe that the selected strategy is satisfactory or right, the work performance can be improved.

Regulation completeness $0\left(\mathcal{C}_{9}\right)$ : This criterion represents the state and level of existing regulations for implementing the selected strategy.

From the above-mentioned criteria "Implementation cost", "Wastage", "Emissions" and "Energy usage" are nonbeneficial criteria which should be minimized and the other criteria are beneficial (i.e. should be maximized). The structure of the problem is shown in Figure 3.

We can say that Figure 3 is the result of Steps 1 and 2 of the proposed approach. Based on Step 3 the members of decision-making group assessed the importance of the each evaluation criterion. These assessments which are made using linguistic variables are presented in Table 2.

Table 2. Assessments related to the importance of the criteria

\begin{tabular}{|l|c|c|c|c|c|c|c|c|c|}
\hline & $\mathcal{G}_{1}$ & $\mathcal{C}_{2}$ & $\mathcal{C}_{3}$ & $\mathcal{C}_{4}$ & $\mathcal{C}_{5}$ & $\mathcal{C}_{6}$ & $\mathcal{C}_{7}$ & $\mathcal{C}_{8}$ & $\mathcal{C}_{9}$ \\
\hline $\mathcal{D}_{1}$ & $\mathrm{H}$ & $\mathrm{ML}$ & $\mathrm{M}$ & $\mathrm{M}$ & $\mathrm{M}$ & $\mathrm{VL}$ & $\mathrm{ML}$ & $\mathrm{L}$ & $\mathrm{ML}$ \\
\hline $\mathcal{D}_{2}$ & $\mathrm{MH}$ & $\mathrm{MH}$ & $\mathrm{M}$ & $\mathrm{MH}$ & $\mathrm{ML}$ & $\mathrm{L}$ & $\mathrm{L}$ & $\mathrm{L}$ & $\mathrm{L}$ \\
\hline $\mathcal{D}_{3}$ & $\mathrm{VH}$ & $\mathrm{MH}$ & $\mathrm{ML}$ & $\mathrm{MH}$ & $\mathrm{M}$ & $\mathrm{L}$ & $\mathrm{ML}$ & $\mathrm{ML}$ & $\mathrm{ML}$ \\
\hline $\mathcal{D}_{4}$ & $\mathrm{H}$ & $\mathrm{M}$ & $\mathrm{ML}$ & $\mathrm{M}$ & $\mathrm{L}$ & $\mathrm{L}$ & $\mathrm{L}$ & $\mathrm{ML}$ & $\mathrm{VL}$ \\
\hline $\mathcal{D}_{5}$ & $\mathrm{MH}$ & $\mathrm{ML}$ & $\mathrm{L}$ & $\mathrm{MH}$ & $\mathrm{L}$ & $\mathrm{ML}$ & $\mathrm{ML}$ & $\mathrm{VL}$ & $\mathrm{ML}$ \\
\hline
\end{tabular}

According to Step 4 of the proposed approach, each strategy (alternative) should be assessed with respect to each criterion. In this step, each DM made his assessments individually using the same linguistic variable of Step 3. The assessments of the decision-making group can be seen in Table 3.

In Step 5, we should calculate the average subjective weights based upon the assessments of the decision-making group in Step 3 and Eqs (26) to (28). The computational results obtained from this step are represented in Table 4.

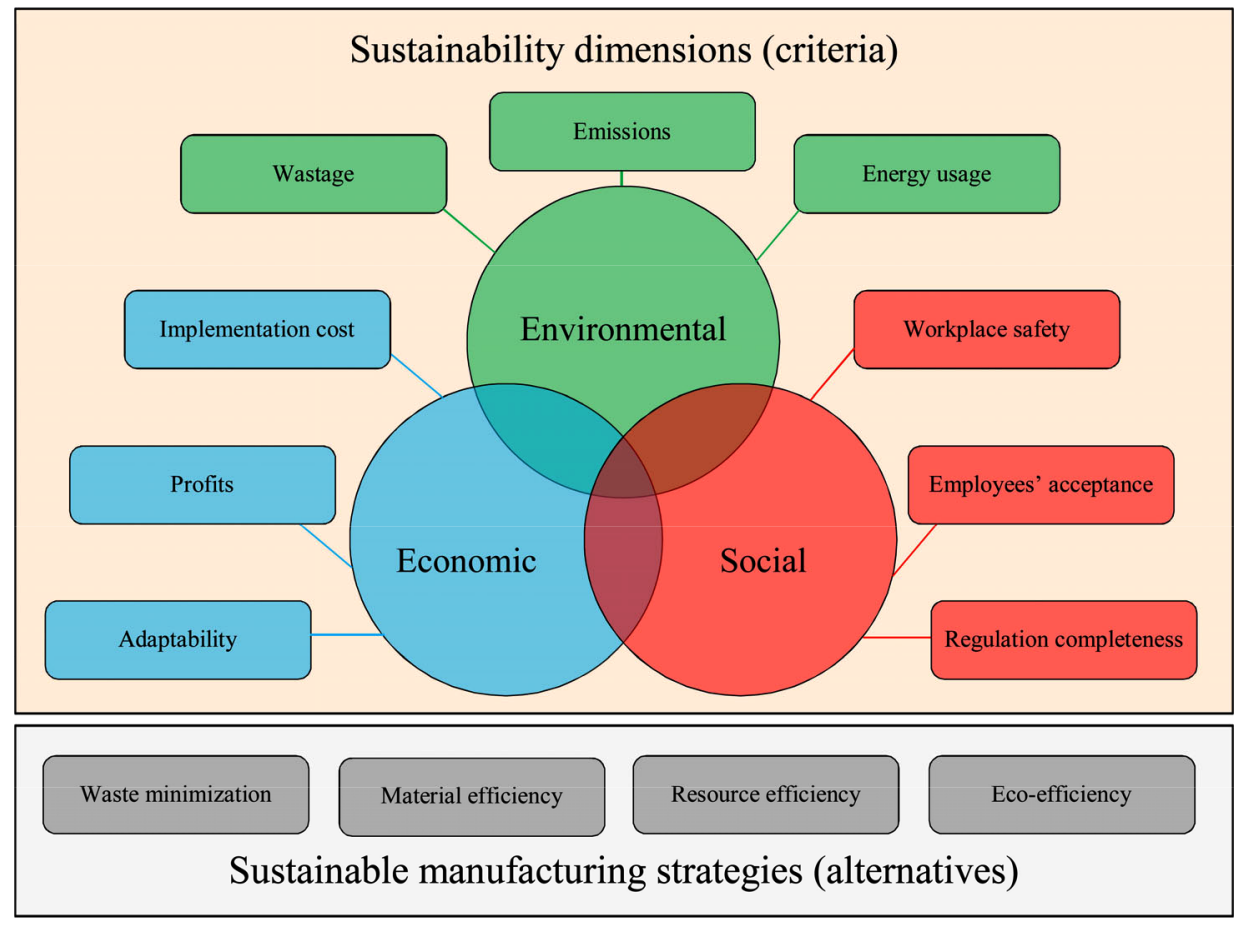

Figure 3. The structure of the problem 
Table 3. Assessments related to the strategies on each criterion

\begin{tabular}{|c|c|c|c|c|c|c|c|c|c|c|}
\hline & $\mathcal{C}_{1}$ & $\mathcal{C}_{2}$ & $\mathcal{C}_{3}$ & $\mathcal{C}_{4}$ & $\mathcal{C}_{5}$ & $\mathcal{C}_{6}$ & $\mathcal{C}_{7}$ & $\mathcal{C}_{8}$ & $\mathcal{C}_{9}$ \\
\hline & & $N C$ & $B C$ & $B C$ & $N C$ & $N C$ & $N C$ & $B C$ & $B C$ & $B C$ \\
\hline \multirow{4}{*}{$\mathcal{D}_{1}$} & $\mathcal{A}_{1}$ & $\mathrm{VH}$ & $\mathrm{H}$ & $\mathrm{H}$ & $\mathrm{VH}$ & $\mathrm{VH}$ & $\mathrm{M}$ & ML & $\mathrm{MH}$ & $\mathrm{L}$ \\
\hline & $\mathcal{A}_{2}$ & $\mathrm{VH}$ & ML & $M$ & $\mathrm{H}$ & ML & $\mathrm{VH}$ & $\mathrm{L}$ & $\mathrm{M}$ & $\mathrm{MH}$ \\
\hline & $\mathcal{A}_{3}$ & $\mathrm{H}$ & $\mathrm{VH}$ & $\mathrm{H}$ & $\mathrm{H}$ & $\mathrm{VH}$ & $\mathrm{VH}$ & $\mathrm{H}$ & ML & $\mathrm{VH}$ \\
\hline & $\mathcal{A}_{4}$ & $\mathrm{M}$ & $\mathrm{VH}$ & $\mathrm{MH}$ & $\mathrm{H}$ & ML & $\mathrm{M}$ & $\mathrm{MH}$ & $\mathrm{VL}$ & ML \\
\hline \multirow{4}{*}{$\mathcal{D}_{2}$} & $\mathcal{A}_{1}$ & $\mathrm{VH}$ & M & $\mathrm{VH}$ & $\mathrm{H}$ & $\mathrm{H}$ & $\mathrm{MH}$ & $\mathrm{MH}$ & $\mathrm{H}$ & VL \\
\hline & $\mathcal{A}_{2}$ & $\mathrm{H}$ & $\mathrm{M}$ & $\mathrm{ML}$ & $\mathrm{H}$ & M & $\mathrm{MH}$ & $\mathrm{M}$ & $\mathrm{M}$ & ML \\
\hline & $\mathcal{A}_{3}$ & $\mathrm{M}$ & $\mathrm{H}$ & $\mathrm{VH}$ & $\mathrm{H}$ & $\mathrm{H}$ & $\mathrm{H}$ & $\mathrm{H}$ & $\mathrm{VL}$ & $\mathrm{H}$ \\
\hline & $\mathcal{A}_{4}$ & $\mathrm{MH}$ & $\mathrm{VH}$ & $\mathrm{VH}$ & $\mathrm{MH}$ & ML & $\mathrm{M}$ & $\mathrm{MH}$ & $\mathrm{L}$ & $\mathrm{VL}$ \\
\hline \multirow{4}{*}{$\mathcal{D}_{3}$} & $\mathcal{A}_{1}$ & $\mathrm{VH}$ & $\mathrm{M}$ & $\mathrm{VH}$ & $\mathrm{H}$ & $\mathrm{H}$ & $\mathrm{M}$ & $\mathrm{M}$ & $\mathrm{MH}$ & VL \\
\hline & $\mathcal{A}_{2}$ & $\mathrm{VH}$ & $\mathrm{M}$ & $\mathrm{ML}$ & $\mathrm{H}$ & $\mathrm{L}$ & $\mathrm{VH}$ & $\mathrm{M}$ & $\mathrm{M}$ & $\mathrm{M}$ \\
\hline & $\mathcal{A}_{3}$ & $\mathrm{M}$ & $\mathrm{MH}$ & $\mathrm{H}$ & $\mathrm{VH}$ & $\mathrm{VH}$ & $\mathrm{H}$ & $\mathrm{MH}$ & $\mathrm{L}$ & $\mathrm{MH}$ \\
\hline & $\mathcal{A}_{4}$ & $\mathrm{M}$ & $\mathrm{H}$ & $\mathrm{VH}$ & $\mathrm{M}$ & $\mathrm{M}$ & $\mathrm{M}$ & $\mathrm{H}$ & $\mathrm{VL}$ & $\mathrm{L}$ \\
\hline \multirow{4}{*}{$\mathcal{D}_{4}$} & $\mathcal{A}_{1}$ & $\mathrm{VH}$ & $\mathrm{H}$ & $\mathrm{H}$ & $\mathrm{H}$ & $\mathrm{H}$ & $\mathrm{H}$ & ML & $\mathrm{H}$ & $\mathrm{L}$ \\
\hline & $\mathcal{A}_{2}$ & $\mathrm{VH}$ & $\mathrm{ML}$ & $\mathrm{ML}$ & $\mathrm{M}$ & M & $\mathrm{MH}$ & M & $\mathrm{MH}$ & $\mathrm{MH}$ \\
\hline & $\mathcal{A}_{3}$ & $\mathrm{M}$ & $\mathrm{H}$ & $\mathrm{MH}$ & $\mathrm{VH}$ & $\mathrm{H}$ & $\mathrm{VH}$ & $\mathrm{M}$ & $\mathrm{VL}$ & $\mathrm{MH}$ \\
\hline & $\mathcal{A}_{4}$ & ML & $\mathrm{VH}$ & $\mathrm{H}$ & $\mathrm{MH}$ & ML & $\mathrm{H}$ & $\mathrm{H}$ & $\mathrm{VL}$ & $\mathrm{L}$ \\
\hline \multirow{4}{*}{$\mathcal{D}_{5}$} & $\mathcal{A}_{1}$ & $\mathrm{H}$ & $\mathrm{M}$ & $\mathrm{H}$ & $\mathrm{H}$ & $\mathrm{H}$ & $\mathrm{M}$ & $\mathrm{M}$ & $\mathrm{M}$ & $\mathrm{L}$ \\
\hline & $\mathcal{A}_{2}$ & $\mathrm{VH}$ & M & ML & $\mathrm{MH}$ & M & $\mathrm{H}$ & $\mathrm{L}$ & $\mathrm{MH}$ & M \\
\hline & $\mathcal{A}_{3}$ & $\mathrm{M}$ & $\mathrm{H}$ & $\mathrm{MH}$ & $\mathrm{H}$ & $\mathrm{VH}$ & $\mathrm{VH}$ & $\mathrm{MH}$ & $\mathrm{VL}$ & $\mathrm{MH}$ \\
\hline & $\mathcal{A}_{4}$ & $\mathrm{M}$ & $\mathrm{VH}$ & $\mathrm{MH}$ & $\mathrm{M}$ & ML & $\mathrm{MH}$ & $\mathrm{VH}$ & $\mathrm{L}$ & $\mathrm{L}$ \\
\hline
\end{tabular}

Table 4 . The average subjective criteria weights

\begin{tabular}{|c|c|c|c|c|c|c|c|c|c|c|}
\hline & \multicolumn{5}{|c|}{$\tilde{w}_{U}^{s}$} & \multicolumn{6}{|c|}{$\tilde{w}_{L}^{s}$} \\
\cline { 2 - 12 } & $a_{U}^{w}$ & $b_{U}^{w}$ & $c_{U}^{w}$ & $d_{U}^{w}$ & $h_{U}^{w}$ & $a_{L}^{w}$ & $b_{L}^{w}$ & $c_{L}^{w}$ & $d_{L}^{w}$ & $h_{L}^{w}$ \\
\hline$\tilde{\tilde{w}}_{1}^{s}$ & 0.191 & 0.238 & 0.249 & 0.278 & 1 & 0.217 & 0.238 & 0.249 & 0.261 & 0.9 \\
\hline$\tilde{\tilde{w}}_{2}^{s}$ & 0.087 & 0.145 & 0.159 & 0.203 & 1 & 0.116 & 0.145 & 0.159 & 0.174 & 0.9 \\
\hline$\tilde{\tilde{w}}_{3}^{s}$ & 0.046 & 0.099 & 0.113 & 0.157 & 1 & 0.072 & 0.099 & 0.113 & 0.128 & 0.9 \\
\hline$\tilde{\tilde{w}}_{4}^{s}$ & 0.122 & 0.18 & 0.194 & 0.238 & 1 & 0.151 & 0.18 & 0.194 & 0.209 & 0.9 \\
\hline$\tilde{\tilde{w}}_{5}^{s}$ & 0.041 & 0.087 & 0.101 & 0.145 & 1 & 0.064 & 0.087 & 0.101 & 0.116 & 0.9 \\
\hline$\tilde{\tilde{w}}_{6}^{s}$ & 0.006 & 0.035 & 0.046 & 0.087 & 1 & 0.02 & 0.035 & 0.046 & 0.061 & 0.9 \\
\hline$\tilde{\tilde{w}}_{7}^{s}$ & 0.017 & 0.064 & 0.078 & 0.122 & 1 & 0.041 & 0.064 & 0.078 & 0.093 & 0.9 \\
\hline$\tilde{\tilde{w}}_{8}^{s}$ & 0.012 & 0.046 & 0.058 & 0.099 & 1 & 0.029 & 0.046 & 0.058 & 0.072 & 0.9 \\
\hline$\tilde{\tilde{w}}_{9}^{s}$ & 0.017 & 0.058 & 0.07 & 0.11 & 1 & 0.038 & 0.058 & 0.07 & 0.084 & 0.9 \\
\hline
\end{tabular}

Step 6 of the proposed approach is related to calculation of the average decision-matrix. This matrix is obtained according to Table 3 and Eqs (29) and (30). To calculate objective weights of criteria, we need to defuzzify the average decision-matrix (Step 7). Then the defuzzified values are used in the SECA model to determine the objective weights and performance scores (Step 8). By solving the SECA model of Step 8 with $\beta=3$ and $\varepsilon=10^{-3}$, the results of Table 5 are derived.

Table 5. The results of solving the SECA model

\begin{tabular}{|c|c|c|c|}
\hline \multicolumn{2}{|c|}{ Objective weights of criteria } & \multicolumn{2}{|c|}{ Performance scores } \\
\hline$w_{1}^{o}$ & 0.0992 & $S e_{1}$ & 0.7050 \\
\hline$w_{2}^{o}$ & 0.1067 & $S e_{2}$ & 0.6431 \\
\hline$w_{3}^{o}$ & 0.1398 & $S e_{3}$ & 0.7149 \\
\hline$w_{4}^{o}$ & 0.1157 & \multirow{2}{*}{$S e_{4}$} & 0.8159 \\
\hline$w_{5}^{o}$ & 0.1055 & & \\
\cline { 1 - 2 }$w_{6}^{o}$ & 0.1343 & & \\
\cline { 1 - 2 }$w_{7}^{o}$ & 0.0993 & & \\
\cline { 1 - 2 }$w_{8}^{o}$ & 0.1105 & & \\
\cline { 1 - 2 }$w_{9}^{o}$ & 0.0890 & & \\
\hline
\end{tabular}

In step 9, the combined weights of criteria are computed according to Eq. (33) and the results of Steps 5 and 8 . The combination parameter $\omega=0.5$ is utilized for computation. In Table 6, we can see the combined weights of each criterion in the form of IT2FSs.

Table 6. The combined weights of criteria

\begin{tabular}{|c|c|c|c|c|c|c|c|c|c|c|}
\hline & \multicolumn{6}{|c|}{$\tilde{w}_{U}^{c}$} & \multicolumn{6}{|c|}{$\tilde{w}_{L}^{c}$} \\
\cline { 2 - 12 } & $a_{U}^{w c}$ & $b_{U}^{w c}$ & $c_{U}^{w c}$ & $d_{U}^{w c}$ & $h_{U}^{w c}$ & $a_{L}^{w c}$ & $b_{L}^{w c}$ & $c_{L}^{w c}$ & $d_{L}^{w c}$ & $h_{L}^{w c}$ \\
\hline$\tilde{\tilde{w}}_{1}^{c}$ & 0.145 & 0.168 & 0.174 & 0.189 & 1 & 0.158 & 0.168 & 0.174 & 0.18 & 0.9 \\
\hline$\tilde{\tilde{w}}_{2}^{c}$ & 0.097 & 0.126 & 0.133 & 0.155 & 1 & 0.111 & 0.126 & 0.133 & 0.14 & 0.9 \\
\hline$\tilde{\tilde{w}}_{3}^{c}$ & 0.093 & 0.119 & 0.126 & 0.148 & 1 & 0.106 & 0.119 & 0.126 & 0.134 & 0.9 \\
\hline$\tilde{\tilde{w}}_{4}^{c}$ & 0.119 & 0.148 & 0.155 & 0.177 & 1 & 0.133 & 0.148 & 0.155 & 0.162 & 0.9 \\
\hline$\tilde{\tilde{w}}_{5}^{c}$ & 0.073 & 0.096 & 0.103 & 0.125 & 1 & 0.085 & 0.096 & 0.103 & 0.111 & 0.9 \\
\hline$\tilde{\tilde{w}}_{6}^{c}$ & 0.07 & 0.085 & 0.09 & 0.111 & 1 & 0.077 & 0.085 & 0.09 & 0.098 & 0.9 \\
\hline$\tilde{\tilde{w}}_{7}^{c}$ & 0.058 & 0.082 & 0.089 & 0.111 & 1 & 0.07 & 0.082 & 0.089 & 0.096 & 0.9 \\
\hline$\tilde{\tilde{w}}_{8}^{c}$ & 0.061 & 0.078 & 0.084 & 0.105 & 1 & 0.07 & 0.078 & 0.084 & 0.091 & 0.9 \\
\hline$\tilde{\tilde{w}}_{9}^{c}$ & 0.053 & 0.073 & 0.079 & 0.1 & 1 & 0.063 & 0.073 & 0.079 & 0.087 & 0.9 \\
\hline
\end{tabular}


Table 7. The normalized decision-matrix of the problem.

\begin{tabular}{|c|c|c|c|c|c|c|c|c|c|c|}
\hline & \multicolumn{5}{|c|}{$\widetilde{X}_{U}$} & \multicolumn{5}{|c|}{$\widetilde{X}_{L}$} \\
\hline & $a_{U}^{X n}$ & $b_{U}^{X n}$ & $c_{U}^{X n}$ & $d_{U}^{X n}$ & $h_{U}^{X n}$ & $a_{L}^{X n}$ & $b_{L}^{X n}$ & $c_{L}^{X n}$ & $d_{L}^{X n}$ & $h_{L}^{X n}$ \\
\hline$\widetilde{\widetilde{X} n_{11}}$ & -0.037 & -0.017 & -0.006 & 0.108 & 1 & -0.027 & -0.017 & -0.006 & 0.046 & 0.9 \\
\hline$\widetilde{\widetilde{X} n_{12}}$ & 0.477 & 0.664 & 0.716 & 0.851 & 1 & 0.581 & 0.664 & 0.716 & 0.768 & 0.9 \\
\hline$\widetilde{\widetilde{X} n_{13}}$ & 0.85 & 0.992 & 1.025 & 1.09 & 1 & 0.937 & 0.992 & 1.025 & 1.057 & 0.9 \\
\hline$\widetilde{\widetilde{X} n_{14}}$ & -0.09 & -0.003 & 0.041 & 0.193 & 1 & -0.046 & -0.003 & 0.041 & 0.095 & 0.9 \\
\hline$\widetilde{\widetilde{X} n_{15}}$ & -0.063 & 0.022 & 0.065 & 0.213 & 1 & -0.02 & 0.022 & 0.065 & 0.118 & 0.9 \\
\hline$\widetilde{\widetilde{X}}_{16}$ & 0.15 & 0.298 & 0.352 & 0.554 & 1 & 0.245 & 0.298 & 0.352 & 0.447 & 0.9 \\
\hline$\widetilde{\widetilde{X} n_{17}}$ & 0.312 & 0.553 & 0.613 & 0.793 & 1 & 0.432 & 0.553 & 0.613 & 0.673 & 0.9 \\
\hline$\widetilde{\widetilde{X} n_{18}}$ & 0.731 & 0.975 & 1.043 & 1.219 & 1 & 0.867 & 0.975 & 1.043 & 1.111 & 0.9 \\
\hline$\widetilde{\widetilde{X} n_{19}}$ & 0 & 0.075 & 0.112 & 0.274 & 1 & 0.037 & 0.075 & 0.112 & 0.175 & 0.9 \\
\hline$\widetilde{\widetilde{X} n_{21}}$ & -0.037 & -0.017 & -0.006 & 0.108 & 1 & -0.027 & -0.017 & -0.006 & 0.046 & 0.9 \\
\hline$\widetilde{\widetilde{X} n_{22}}$ & 0.228 & 0.436 & 0.488 & 0.643 & 1 & 0.332 & 0.436 & 0.488 & 0.539 & 0.9 \\
\hline$\widetilde{\widetilde{X} n_{23}}$ & 0.53 & 0.371 & 0.425 & 0.589 & 1 & 0.262 & 0.371 & 0.425 & 0.48 & 0.9 \\
\hline$\widetilde{\widetilde{X} n_{24}}$ & -0.003 & 0.128 & 0.183 & 0.368 & 1 & 0.074 & 0.128 & 0.183 & 0.259 & 0.9 \\
\hline$\widetilde{\widetilde{X}}_{25}$ & 0.383 & 0.543 & 0.596 & 0.787 & 1 & 0.49 & 0.543 & 0.596 & 0.692 & 0.9 \\
\hline$\widetilde{\widetilde{X}}_{26}$ & -0.02 & 0.065 & 0.096 & 0.256 & 1 & 0.033 & 0.065 & 0.096 & 0.171 & 0.9 \\
\hline$\widetilde{\widetilde{X}}_{27}$ & 0.216 & 0.408 & 0.469 & 0.649 & 1 & 0.312 & 0.408 & 0.469 & 0.529 & 0.9 \\
\hline$\widetilde{\widetilde{X} n_{28}}$ & 0.515 & 0.786 & 0.853 & 1.057 & 1 & 0.65 & 0.786 & 0.853 & 0.921 & 0.9 \\
\hline$\widetilde{\widetilde{X} n_{29}}$ & 0.424 & 0.674 & 0.736 & 0.923 & 1 & 0.549 & 0.674 & 0.736 & 0.798 & 0.9 \\
\hline$\widetilde{\widetilde{X} n_{31}}$ & 0.212 & 0.357 & 0.409 & 0.606 & 1 & 0.305 & 0.357 & 0.409 & 0.502 & 0.9 \\
\hline$\widetilde{\widetilde{X} n_{32}}$ & 0.726 & 0.882 & 0.923 & 1.017 & 1 & 0.819 & 0.882 & 0.923 & 0.965 & 0.9 \\
\hline$\widetilde{\widetilde{X}}_{33}$ & 0.719 & 0.894 & 0.937 & 1.046 & 1 & 0.817 & 0.894 & 0.937 & 0.981 & 0.9 \\
\hline$\widetilde{\widetilde{X}}_{34}$ & -0.09 & -0.025 & 0.008 & 0.15 & 1 & -0.057 & -0.025 & 0.008 & 0.063 & 0.9 \\
\hline$\widetilde{\widetilde{X}}_{35}$ & -0.063 & -0.02 & 0.001 & 0.128 & 1 & -0.042 & -0.02 & 0.001 & 0.054 & 0.9 \\
\hline$\widetilde{\widetilde{X}}_{36}$ & -0.063 & -0.02 & 0.001 & 0.128 & 1 & -0.042 & -0.02 & 0.001 & 0.054 & 0.9 \\
\hline$\widetilde{\widetilde{X}}_{37}$ & 0.649 & 0.865 & 0.925 & 1.081 & 1 & 0.769 & 0.865 & 0.925 & 0.985 & 0.9 \\
\hline$\widetilde{\widetilde{X}}_{38}$ & 0.027 & 0.108 & 0.135 & 0.298 & 1 & 0.068 & 0.108 & 0.135 & 0.203 & 0.9 \\
\hline$\widetilde{\widetilde{X} n_{39}}$ & 0.773 & 0.986 & 1.035 & 1.173 & 1 & 0.886 & 0.986 & 1.035 & 1.085 & 0.9 \\
\hline$\widetilde{\widetilde{X}}_{41}$ & 0.274 & 0.429 & 0.481 & 0.689 & 1 & 0.378 & 0.429 & 0.481 & 0.585 & 0.9 \\
\hline$\widetilde{\widetilde{X}}_{42}$ & 0.892 & 1.006 & 1.017 & 1.037 & 1 & 0.954 & 1.006 & 1.017 & 1.027 & 0.9 \\
\hline$\widetilde{\widetilde{X}}_{43}$ & 0.763 & 0.926 & 0.959 & 1.046 & 1 & 0.85 & 0.926 & 0.959 & 0.992 & 0.9 \\
\hline$\widetilde{\widetilde{X}}_{44}$ & 0.084 & 0.237 & 0.292 & 0.499 & 1 & 0.183 & 0.237 & 0.292 & 0.39 & 0.9 \\
\hline$\widetilde{\widetilde{X}}_{45}$ & 0.426 & 0.585 & 0.639 & 0.851 & 1 & 0.532 & 0.585 & 0.639 & 0.745 & 0.9 \\
\hline$\widetilde{\widetilde{X}}_{46}$ & 0.15 & 0.298 & 0.352 & 0.554 & 1 & 0.245 & 0.298 & 0.352 & 0.447 & 0.9 \\
\hline$\widetilde{\widetilde{X}}_{47}$ & 0.793 & 0.985 & 1.033 & 1.153 & 1 & 0.901 & 0.985 & 1.033 & 1.081 & 0.9 \\
\hline$\widetilde{\widetilde{X}}_{48}$ & 0 & 0.054 & 0.081 & 0.244 & 1 & 0.027 & 0.054 & 0.081 & 0.149 & 0.9 \\
\hline$\widetilde{\widetilde{X}}_{49}$ & 0.025 & 0.15 & 0.2 & 0.374 & 1 & 0.087 & 0.15 & 0.2 & 0.262 & 0.9 \\
\hline
\end{tabular}


Table 8. The WASPAS measure for each strategy

\begin{tabular}{|c|c|c|c|c|c|c|c|c|c|c|}
\hline & \multicolumn{9}{|c|}{$\tilde{Q}_{U}$} & \multicolumn{5}{c|}{$\tilde{Q}_{L}$} \\
\cline { 2 - 11 } & $a_{U}^{Q}$ & $b_{U}^{Q}$ & $c_{U}^{Q}$ & $d_{U}^{Q}$ & $h_{U}^{Q}$ & $a_{L}^{Q}$ & $b_{L}^{Q}$ & $c_{L}^{Q}$ & $d_{L}^{Q}$ & $h_{L}^{Q}$ \\
\hline$\widetilde{Q}_{1}$ & 0.54 & 0.741 & 0.814 & 1.09 & 1 & 0.644 & 0.741 & 0.814 & 0.913 & 0.9 \\
\hline$\widetilde{Q}_{2}$ & 0.486 & 0.708 & 0.785 & 1.091 & 1 & 0.596 & 0.708 & 0.785 & 0.894 & 0.9 \\
\hline$\widetilde{\widetilde{Q}}_{3}$ & 0.606 & 0.823 & 0.896 & 1.175 & 1 & 0.72 & 0.823 & 0.896 & 1.001 & 0.9 \\
\hline$\widetilde{\tilde{Q}}_{4}$ & 0.706 & 0.952 & 1.034 & 1.348 & 1 & 0.84 & 0.952 & 1.034 & 1.16 & 0.9 \\
\hline
\end{tabular}

The normalized decision-matrix is calculated according to the average decision-matrix and formulas presented in Step 10 of the proposed approach. The normalization process of the average decision-matrix depends on the type of the criteria. As previously mentioned, some of the criteria are beneficial $(B C)$ and some are non-beneficial $(N C)$. Table 7 represents the normalized decision-matrix elements in the form of type-2 fuzzy sets.

According to the computed normalized decision-matrix elements and Eqs (35) to (38), we can calculate the normalized WSM and WPM measures (Step 11). Then the WASPAS measure can be computed based on Eq. (39). We use $\gamma=0.5$ for the parameter of the WASPAS measure. The IT2FSs associated with the normalized WSM and WPM measures are shown in Table 8.

Finally, the aggregated scores of the alternatives can be determined according to the WASPAS measure and performance scores of SECA. In this step, the ranking value of the WASPAS measure for each alternative should be calculated according to the ranking method described in Section 1.2. In Table 9, the ranking values, performance scores of SECA and the aggregated scores are presented. The aggregated scores can be used as a measure for evaluation of sustainable manufacturing strategies.

Table 9. The final scores for evaluation of strategies

\begin{tabular}{|c|c|c|c|c|}
\hline Strategies & $R v\left(\widetilde{\tilde{Q}}_{i}\right)$ & $S e_{i}$ & $A S_{i}$ & Rank \\
\hline $\mathcal{A}_{1}$ & 0.1980 & 0.7050 & 0.9031 & 3 \\
\hline $\mathcal{A}_{2}$ & 0.1353 & 0.6431 & 0.7784 & 4 \\
\hline $\mathcal{A}_{3}$ & 0.2917 & 0.7149 & 1.0066 & 2 \\
\hline $\mathcal{A}_{4}$ & 0.3750 & 0.8159 & 1.1909 & 1 \\
\hline
\end{tabular}

As can be seen in Table $9, \mathcal{A}_{4}$ has the highest performance among the alternatives. Therefore, "Eco-efficiency" is the best strategy for the company with respect to the assessments of the experts of the decision-making group. According to the aggregated scores $\mathcal{A}_{3}$ or "Resource efficiency" is the second best strategy which the company can follow.

\section{Sensitivity analysis}

Although the methodology gives a solid strategy as the best alternative, we should examine if the result is stable or not. For this purpose, we should design an analysis that can reflect the impact of variations in some parameters or sensitivity of the proposed method. In this section, based on a wavering pattern shown in Figure 4, we analyse the sensitivity of the results by means of variation in the weights of criteria. We choose the weights of criteria as the sensitivity analysis parameter because this parameter is very subjective and can be more changeable than the other parameters. As can be seen in Figure 4, there are nine sets for the criteria weights.

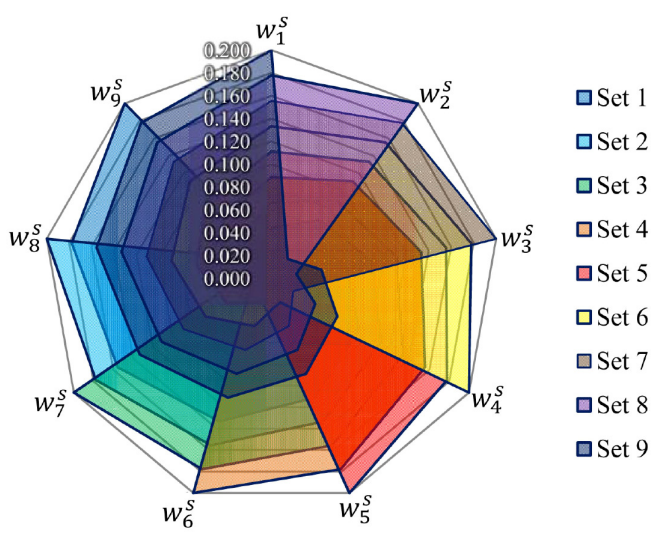

Figure 4 . The wavering pattern of criteria weights for sensitivity analysis

In each of the sets, there are a minimum weight, a maximum weight and some other weights between the minimum and maximum values. According to these nine sets, the problem of evaluating sustainable manufacturing strategies, which has been addressed in the previous section, is solved nine times using the proposed approach. The weights of the defined sets are replaced with $\widetilde{\tilde{w}}_{j}^{s}$ in Eq. (33). A rank is obtained for each of the alternatives in each run of the proposed approach. The aggregated scores and the rank of the alternatives in each set are presented in Table 10, and the diagrammatic representation of them is shown in Figure 5. As it can be seen, the aggregated score and rank of $\mathcal{A}_{4}$ or "Eco-efficiency" strategy are completely stable. Therefore, we can choose this strategy 
even if the weights of criteria are changed. The second best strategy, on the other hand, can be changed by varying criteria weights. In Set 2 and Set $4, \mathcal{A}_{1}$ or "Waste minimization" is ranked as the second best strategy; however, $\mathcal{A}_{3}$ or "Resource efficiency" is the second best strategy in the other sets. The aggregated score of $\mathcal{A}_{2}$ (Material efficiency) is almost steady in all sets, and it can be considered as the worst alternative or strategy. From the results provided, it can be concluded that the proposed approach yields relatively stable results.

Table 10 . The results of the sensitivity analysis

\begin{tabular}{|c|c|c|c|c|c|}
\hline & & $\mathcal{A}_{1}$ & $\mathcal{A}_{2}$ & $\mathcal{A}_{3}$ & $\mathcal{A}_{4}$ \\
\hline \multirow{2}{*}{ Set 1} & $A S_{i}$ & 0.8956 & 0.8211 & 0.9714 & 1.1909 \\
\hline & Rank & 3 & 4 & 2 & 1 \\
\hline \multirow{2}{*}{ Set 2} & $A S_{i}$ & 0.9967 & 0.8233 & 0.868 & 1.1909 \\
\hline & Rank & 2 & 4 & 3 & 1 \\
\hline \multirow{2}{*}{ Set 3} & $A S_{i}$ & 0.9172 & 0.7681 & 1.0027 & 1.1909 \\
\hline & Rank & 3 & 4 & 2 & 1 \\
\hline \multirow{2}{*}{ Set 4} & $A S_{i}$ & 0.9651 & 0.7681 & 0.9548 & 1.1909 \\
\hline & Rank & 2 & 4 & 3 & 1 \\
\hline \multirow{2}{*}{ Set 5} & $A S_{i}$ & 0.8892 & 0.7923 & 1.0066 & 1.1909 \\
\hline & Rank & 3 & 4 & 2 & 1 \\
\hline \multirow{2}{*}{ Set 6} & $A S_{i}$ & 0.9134 & 0.7681 & 1.0066 & 1.1909 \\
\hline & Rank & 3 & 4 & 2 & 1 \\
\hline \multirow{2}{*}{ Set 7} & $A S_{i}$ & 0.9134 & 0.7681 & 1.0066 & 1.1909 \\
\hline & Rank & 3 & 4 & 2 & 1 \\
\hline \multirow{2}{*}{ Set 8} & $A S_{i}$ & 0.9116 & 0.7699 & 1.0066 & 1.1909 \\
\hline & Rank & 3 & 4 & 2 & 1 \\
\hline \multirow{2}{*}{ Set 9} & $A S_{i}$ & 0.8728 & 0.8087 & 1.0066 & 1.1909 \\
\hline & Rank & 3 & 4 & 2 & 1 \\
\hline
\end{tabular}
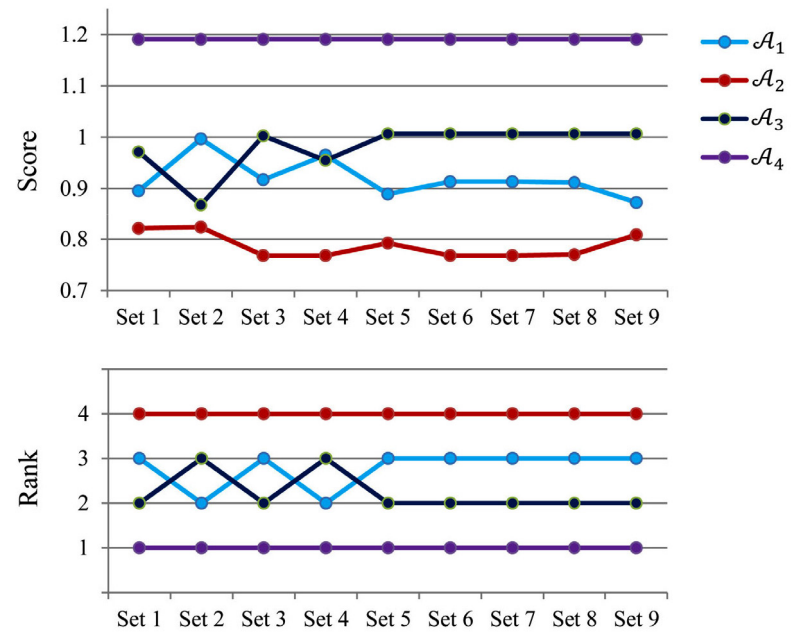

Figure 5. Variations in the aggregated scores and rank of the strategies

\section{Conclusions}

If we consider manufacturing as one of the main pillars of civilized lifestyle, it can play an essential role in moving toward sustainability. To save the environment and improve human's quality of life, manufacturing industries should take sustainable manufacturing models as one of the important environmental efforts. Implementing sustainable manufacturing models needs to select a good strategy which is consistent with the type of business. Evaluation of different strategies is usually a subjective process that could intrinsically subject to some level of uncertainty. In the current study, a novel hybrid decision model has been developed for evaluating sustainable manufacturing strategies under uncertainty. The uncertainty of information has been modeled by means of interval type- 2 fuzzy sets in order to have a flexible evaluation process. Two multi-criteria decision-making methods have been the foundation of the evaluation process: SECA and WASPAS. We have defined the assessments of experts or decisionmakers about the level of alternatives' performance and the level of importance of each criterion in the form of IT2FSs. Then, according to the defuzzified decision-matrix and the SECA method, objective criteria weights and alternatives' performance scores have been calculated. To achieve more practical weights for criteria, we have defined combined weights based on the calculated objective weights and the subjective weights elicited from experts' assessments. For making final evaluation of strategies, the aggregated scores, which are a combination of the WASPAS measure and the performance score of SECA, have been computed. We have presented an example to illustrate the proposed approach for evaluation of sustainable manufacturing strategies. Also, to evidence the stability and robustness of the findings, an analysis has been designed and carried out based on changing criteria weights. The results showed that the developed decision-making methodology is suitable for this evaluation problem, and the final ranking of strategies is stable when the criteria weights are changed.

\section{References}

Abdul Rashid, S. H., Evans, S., \& Longhurst, P. (2008). A comparison of four sustainable manufacturing strategies. International Journal of Sustainable Engineering, 1(3), 214-229. https://doi.org/10.1080/19397030802513836

Abdullah, I., Wan Mahmood, W. H., Md Fauadi, H. F., Ab Rahman, M. N., \& Mohamed, S. B. (2017). Sustainable manufacturing practices in Malaysian palm oil mills: Priority and current performance. Journal of Manufacturing Technology Management, 28(3), 278-298.

https://doi.org/10.1108/jmtm-09-2016-0128

Bhanot, N., Rao, P. V., \& Deshmukh, S. (2017). An integrated approach for analysing the enablers and barriers of sustainable manufacturing. Journal of Cleaner Production, 142, 44124439. https://doi.org/10.1016/j.jclepro.2016.11.123

Canadian Manufacturing Sector Gateway. (2019). Sustainable manufacturing. Retrieved from https://www.ic.gc.ca/eic/site/ mfg-fab.nsf/eng/h_00193.html 
Celik, E., Gul, M., Aydin, N., Gumus, A. T., \& Guneri, A. F. (2015). A comprehensive review of multi criteria decision making approaches based on interval type- 2 fuzzy sets. Knowledge-Based Systems, 85, 329-341. https://doi.org/10.1016/j.knosys.2015.06.004

Chen, S.-M., \& Lee, L.-W. (2010). Fuzzy multiple attributes group decision-making based on the ranking values and the arithmetic operations of interval type- 2 fuzzy sets. Expert Systems with Applications, 37(1), 824-833.

https://doi.org/10.1016/j.eswa.2009.06.094

Chu, T.-C., \& Tsao, C.-T. (2002). Ranking fuzzy numbers with an area between the centroid point and original point. Computers \& Mathematics with Applications, 43(1-2), 111-117. https://doi.org/10.1016/s0898-1221(01)00277-2

Hamdan, S., \& Cheaitou, A. (2017). Supplier selection and order allocation with green criteria: An MCDM and multi-objective optimization approach. Computers \& Operations Research, 81, 282-304. https://doi.org/10.1016/j.cor.2016.11.005

Heydari, M., Honarbakhsh, A., Pajoohesh, M., \& Zangiabadi, M. (2018). Land use optimization using the fuzzy mathematicalspatial approach: a case study of Chelgerd watershed, Iran. Journal of Environmental Engineering and Landscape Management, 26(2), 75-87.

https://doi.org/10.3846/16486897.2017.1350688

Joung, C. B., Carrell, J., Sarkar, P., \& Feng, S. C. (2013). Categorization of indicators for sustainable manufacturing. Ecological Indicators, 24, 148-157.

https://doi.org/10.1016/j.ecolind.2012.05.030

Keshavarz-Ghorabaee, M., Amiri, M., Zavadskas, E. K., Turskis, Z., \& Antucheviciene, J. (2018). Simultaneous evaluation of criteria and alternatives (SECA) for multi-criteria decisionmaking. Informatica, 29(2), 265-280.

https://doi.org/10.15388/informatica.2018.167

Keshavarz Ghorabaee, M., Amiri, M., Sadaghiani, J. S., \& Goodarzi, G. H. (2014). Multiple criteria group decision-making for supplier selection based on COPRAS method with interval type-2 fuzzy sets. International Journal of Advanced Manufacturing Technology, 75(5-8), 1115-1130.

https://doi.org/10.1007/s00170-014-6142-7

Keshavarz Ghorabaee, M., Amiri, M., Salehi Sadaghiani, J., \& Zavadskas, E. K. (2015). Multi-criteria project selection using an extended VIKOR method with interval type-2 fuzzy sets. International Journal of Information Technology \& Decision Making, 14(5), 993-1016. https://doi.org/10.1142/s0219622015500212

Kumar, A., Shankar, R., \& Thakur, L. S. (2018). A big data driven sustainable manufacturing framework for condition-based maintenance prediction. Journal of Computational Science, 27, 428-439. https://doi.org/10.1016/j.jocs.2017.06.006

Liao, H., Xu, Z., Herrera-Viedma, E., \& Herrera, F. (2018). Hesitant fuzzy linguistic term set and its application in decision making: a state-of-the-art survey. International Journal of Fuzzy Systems, 20(7), 2084-2110.

https://doi.org/10.1007/s40815-017-0432-9

Liu, P., Chen, S.-M., \& Wang, P. (2018). Multiple-attribute group decision-making based on q-rung orthopair fuzzy power maclaurin symmetric mean operators. IEEE Transactions on Systems, Man, and Cybernetics: Systems.

https://doi.org/10.1109/tsmc.2018.2852948

Liu, P., Gao, H., \& Ma, J. (2019). Novel green supplier selection method by combining quality function deployment with partitioned Bonferroni mean operator in interval type-2 fuzzy environment. Information Sciences, 490, 292-316.

https://doi.org/10.1016/j.ins.2019.03.079
Liu, P., \& Liu, J. (2018). Some q-rung orthopai fuzzy Bonferroni mean operators and their application to multi-attribute group decision making. International Journal of Intelligent Systems, 33(2), 315-347. https://doi.org/10.1002/int.21933

Liu, P., \& Wang, P. (2018a). Multiple-attribute decision-making based on Archimedean Bonferroni Operators of q-rung orthopair fuzzy numbers. IEEE Transactions on Fuzzy systems, 27(5), 834-848. https://doi.org/10.1109/tfuzz.2018.2826452

Liu, P., \& Wang, P. (2018b). Some q-rung orthopair fuzzy aggregation operators and their applications to multiple-attribute decision making. International Journal of Intelligent Systems, 33(2), 259-280. https://doi.org/10.1002/int.21927

Mardani, A., Jusoh, A., Md Nor, K., Khalifah, Z., Zakwan, N., \& Valipour, A. (2015). Multiple criteria decision-making techniques and their applications - a review of the literature from 2000 to 2014. Economic Research-Ekonomska Istraživanja, 28(1), 516-571.

https://doi.org/10.1080/1331677x.2015.1075139

Maxwell, D., Sheate, W., \& van der Vorst, R. (2006). Functional and systems aspects of the sustainable product and service development approach for industry. Journal of Cleaner Production, 14(17), 1466-1479.

https://doi.org/10.1016/j.jclepro.2006.01.028

Mebratu, D. (1998). Sustainability and sustainable development: historical and conceptual review. Environmental Impact Assessment Review, 18(6), 493-520.

https://doi.org/10.1016/S0195-9255(98)00019-5

Mendel, J. M., John, R. I., \& Liu, F. L. (2006). Interval type-2 fuzzy logic systems made simple. IEEE Transactions on Fuzzy Systems, 14(6), 808-821.

https://doi.org/10.1109/tfuzz.2006.879986

Ocampo, L. A., Clark, E. E., \& Promentilla, M. A. B. (2016). Computing sustainable manufacturing index with fuzzy analytic hierarchy process. International Journal of Sustainable Engineering, 9(5), 305-314.

https://doi.org/10.1080/19397038.2016.1144828

Ocampo, L. A., \& Estanislao-Clark, E. (2014). Developing a framework for sustainable manufacturing strategies selection. DLSU Business \& Economics Review, 23, 115-131.

Porter, M. (1996). America's green strategy. In R. Welford \& R. Starkey (Eds.), Business and the environment: a reader. London, UK: Earthscan.

Qin, J. (2019). A survey of type-2 fuzzy aggregation and application for multiple criteria decision making. Journal of Data, Information and Management. https://doi.org/10.1007/s42488-019-00002-1

Rajak, S., \& Vinodh, S. (2015). Application of fuzzy logic for social sustainability performance evaluation: a case study of an Indian automotive component manufacturing organization. Journal of Cleaner Production, 108, 1184-1192. https://doi.org/10.1016/j.jclepro.2015.05.070

Shankar, K. M., Kumar, P. U., \& Kannan, D. (2016). Analyzing the drivers of advanced sustainable manufacturing system using AHP approach. Sustainability, 8(8), 824. https://doi.org/10.3390/su8080824

Singh, S., Olugu, E. U., Musa, S. N., \& Mahat, A. B. (2018). Fuzzy-based sustainability evaluation method for manufacturing SMEs using balanced scorecard framework. Journal of Intelligent Manufacturing, 29(1), 1-18.

https://doi.org/10.1007/s10845-015-1081-1

Singh, S., Olugu, E. U., Musa, S. N., Mahat, A. B., \& Wong, K. Y. (2016). Strategy selection for sustainable manufacturing with integrated AHP-VIKOR method under interval-valued fuzzy 
environment. The International Journal of Advanced Manufacturing Technology, 84(1), 547-563.

https://doi.org/10.1007/s00170-015-7553-9

Teng, F., Liu, Z., \& Liu, P. (2018). Some power Maclaurin symmetric mean aggregation operators based on Pythagorean fuzzy linguistic numbers and their application to group decision making. International Journal of Intelligent Systems, 33(9), 1949-1985. https://doi.org/10.1002/int.22005

Thirupathi, R., \& Vinodh, S. (2016). Application of interpretive structural modelling and structural equation modelling for analysis of sustainable manufacturing factors in Indian automotive component sector. International Journal of Production Research, 54(22), 6661-6682. https://doi.org/10.1080/00207543.2015.1126372

United States Environmental Protection Agency. (2019). Sustainable manufacturing. Retrieved from https://www.epa.gov/sustainability/sustainable-manufacturing.

Vimal, K., \& Vinodh, S. (2016). LCA integrated ANP framework for selection of sustainable manufacturing processes. Environmental Modeling \& Assessment, 21(4), 507-516. https://doi.org/10.1007/s10666-015-9490-2

Vinodh, S., \& Girubha, R. J. (2012a). Sustainable concept selection using ELECTRE. Clean Technologies and Environmental Policy, 14(4), 651-656. https://doi.org/10.1007/s10098-011-0429-2

Vinodh, S., \& Jeya Girubha, R. (2012b). PROMETHEE based sustainable concept selection. Applied Mathematical Modelling, 36(11), 5301-5308. https://doi.org/10.1016/j.apm.2011.12.030

Wang, Y.-M., Yang, J.-B., Xu, D.-L., \& Chin, K.-S. (2006). On the centroids of fuzzy numbers. Fuzzy Sets and Systems, 157(7), 919-926. https://doi.org/10.1016/j.fss.2005.11.006
Wu, H., Xu, Z., Ren, P., \& Liao, H. (2018). Hesitant fuzzy linguistic projection model to multi-criteria decision making for hospital decision support systems. Computers \& Industrial Engineering, 115, 449-458.

https://doi.org/10.1016/j.cie.2017.11.023

$\mathrm{Xu}, \mathrm{Z}$. (2005). Deviation measures of linguistic preference relations in group decision making. Omega, 33(3), 249-254. https://doi.org/10.1016/j.omega.2004.04.008

$\mathrm{Xu}, \mathrm{Z}$. (2015). Uncertain multi-attribute decision making: Methods and applications. Berlin: Springer. https://doi.org/10.1007/978-3-662-45640-8

$\mathrm{Xu}, \mathrm{Z}$., \& Wang, H. (2017). On the syntax and semantics of virtual linguistic terms for information fusion in decision making. Information Fusion, 34, 43-48. https://doi.org/10.1016/j.inffus.2016.06.002

Zadeh, L. A. (1965). Fuzzy sets. Information and Control, 8(3), 338-353. https://doi.org/10.1016/s0019-9958(65)90241-x

Zadeh, L. A. (1975). The concept of a linguistic variable and its application to approximate reasoning - I. Information Sciences, 8(3), 199-249. https://doi.org/10.1016/0020-0255(75)90036-5

Zavadskas, E. K., Turskis, Z., Antucheviciene, J., \& Zakarevicius, A. (2012). Optimization of weighted aggregated sum product assessment. Elektronika ir elektrotechnika, 122(6), 3-6. https://doi.org/10.5755/j01.eee.122.6.1810

Zhou, Z., Dou, Y., Zhang, X., Zhao, D., \& Tan, Y. (2018). A group decision-making model for wastewater treatment plans selection based on intuitionistic fuzzy sets. Journal of Environmental Engineering and Landscape Management, 26(4), 251-260. https://doi.org/10.3846/jeelm.2018.6122 